\title{
Validations of CFD Code for Density-Gradient Driven Air Ingress Stratified Flow
}

\section{ICONE 18}

\author{
Chang H. Oh
}

Eung S. Kim

The INL is a

U.S. Department of Energy

National Laboratory

operated by

Battelle Energy Alliance

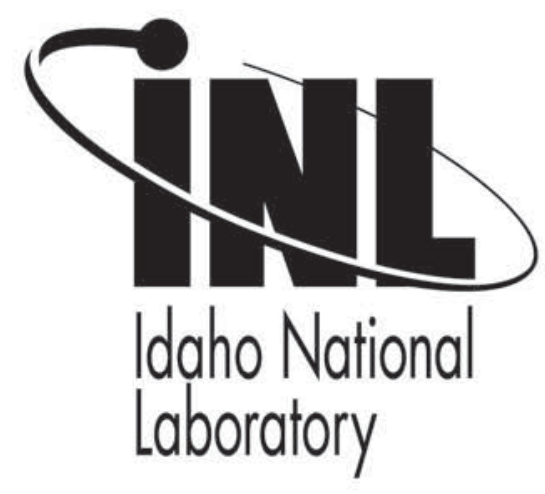

\section{May 2010}

This is a preprint of a paper intended for publication in a journal or proceedings. Since changes may be made before publication, this preprint should not be cited or reproduced without permission of the author. This document was prepared as an account of work sponsored by an agency of the United States Government. Neither the United States Government nor any agency thereof, or any of their employees, makes any warranty, expressed or implied, or assumes any legal liability or responsibility for any third party's use, or the results of such use, of any information, apparatus, product or process disclosed in this report, or represents that its use by such third party would not infringe privately owned rights. The views expressed in this paper are not necessarily those of the United States Government or the sponsoring agency. 


\title{
ICONE18-29807
}

\section{VALIDATIONS OF CFD CODE FOR DENSITY-GRADIENT DRIVEN AIR INGRESS STRATIFIED FLOW}

\author{
Chang $\mathrm{H}$. Oh and Eung S. Kim \\ Idaho National Laboratory \\ Idaho Falls, Idaho 83415 \\ Email: Chang.Oh@inl.gov
}

\section{ABSTRACT}

Air ingress into a very high temperature gas-cooled reactor (VHTR) is an important phenomenon to consider because the air oxidizes the reactor core and lower plenum where the graphite structure supports the core region in the gas turbine modular helium reactor (GTMHR) design, thus jeopardizing the reactor's safety. Validating the computational fluid dynamics (CFD) code used to analyze the air ingress phenomena is therefore an essential part of the safety analysis and the ultimate computation required for licensing.

An experimental data set collected by ETH Zurich on a lock exchange experiment (Grobelbauser et al., Lowe et al. 2002; Lowe et al. 2005; and Shin et al. 2004) was selected for the validation. The experiment was based on a series of lock exchange flows with gases of different density ratios varying from 0.046 to 0.9 in a closed channel of a square cross-section. The focus was on the quantitative measurement of front velocities of the gravity current flows. The experiment results cover the full range of gas intrusions - heavy as well as lightfor the gravity current flows in the lock exchange situations.

FLUENT CFD code (ANSYS Fluent 2008) was used. The calculated results showed very good agreement with the experimental data. A number of tables and comparison plots are included to summarize the estimated current speeds. The current speed obtained by experimental data was $1.25 \mathrm{~m} / \mathrm{s}$ and that of the simulation was $1.19 \mathrm{~m} / \mathrm{s}$. This result indicates that the deviation of the simulation is only $4.8 \%$ that of the experimental data.

\section{DESCRIPTION OF EXPERIMENTS}

An experimental loop was set up by Grobelbauer et al. (1993) in ETH Zurich as a part of code validation. Their experiments are based on a series of lock exchange flows with gases of different densities in a closed channel of a square cross-section. They focused on the quantitative measurement of front velocities of the gravity current flows. The experiment results cover the full range of gas intrusions - heavy as well as light - for the gravity current flows in lock exchange situations.

Figure 1 shows the experimental setup. A closed channel of cross-section $0.3 \times 0.3 \mathrm{~m}^{2}$ and total length of either 3.8 or $4.5 \mathrm{~m}$ is divided into chambers of unequal size separated by a quick-operating gate. The chamber lengths are 3.8 and $0.8 \mathrm{~m}$ (or $1.5 \mathrm{~m}$ ), respectively. The chambers were filled with gases of different densities, and to this end they were equipped with valves at the end walls. A gas heavier than air was supplied through the low valve and air let out through the top valve; vice versa for gases lighter than air. The concentration of gas in the chambers was monitored during the filling process; prior to a test it was above $95 \%$ for the large chamber and above $97 \%$ for the smaller chamber. The temperature was also monitored; prior to a test the 
temperature difference relative to the ambient was always less than $2^{\circ} \mathrm{C}$.

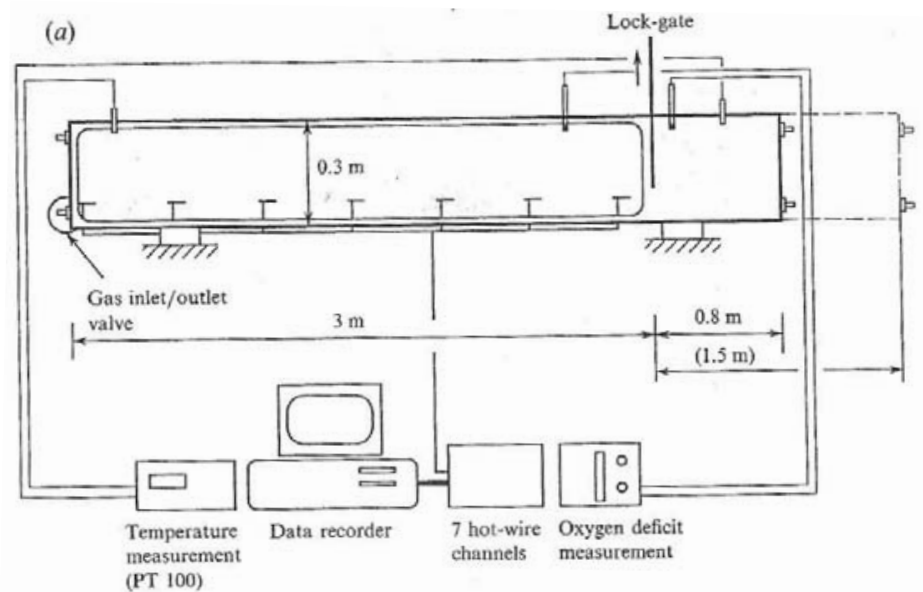

Figure 1. Experimental arrangement (Grobelbauser et al. 1993).

According to Grobelbauser et al. (1993), the experimental scatter is mainly contributed by the manually opened gate. However, the time required to open the gate was very short compared to characteristic flow times. The gate velocity was reported to be $3-4 \mathrm{~m} / \mathrm{s}$, while flow velocity was reported to be $0.2-1.8 \mathrm{~m} / \mathrm{s}$. The velocity of the front was measured by using seven hotwire probes placed along the floor (for heavy gas) as shown in Figure 2, or along the ceiling (for lighter gas) as shown in Figure 3. These probes were used as trip wires to give the signal of the arrival time of the current front. Figures 2 and 3 show the propagation velocities of the fronts of heavy gas and light gas, respectively. The experiment was conducted with combinations of five different gases: air, argon, carbon dioxide, Freon 22, and helium, producing density ratios ranging from 0.046 to 0.9 . Seven different gas combinations were taken into consideration (See Table 1). Each gas combination was tested in two configurations: first with the heavy gas in the smaller chamber and the light gas in the larger chamber, then vice versa.

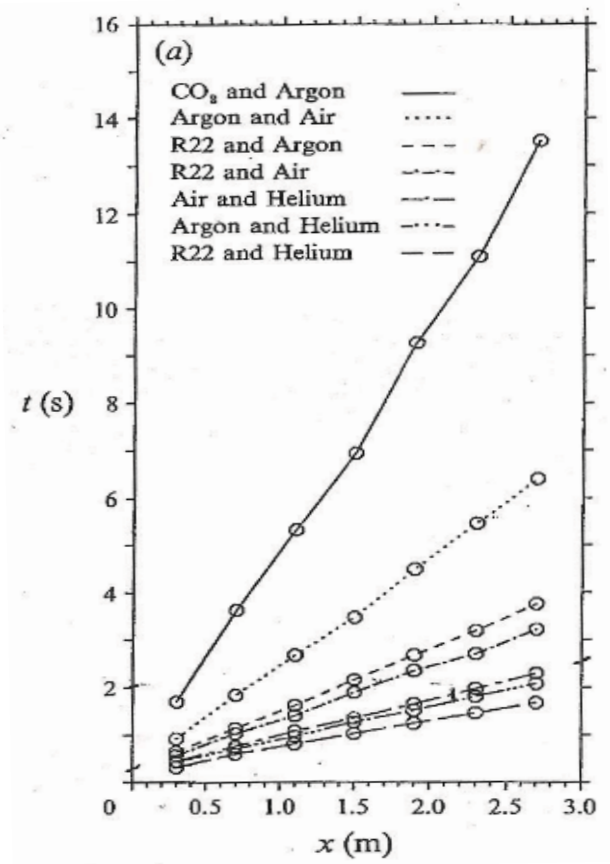

Figure 2. Propagation velocities of dense gas and light gases (Grobelbauser et al. 1993)—dense gas.

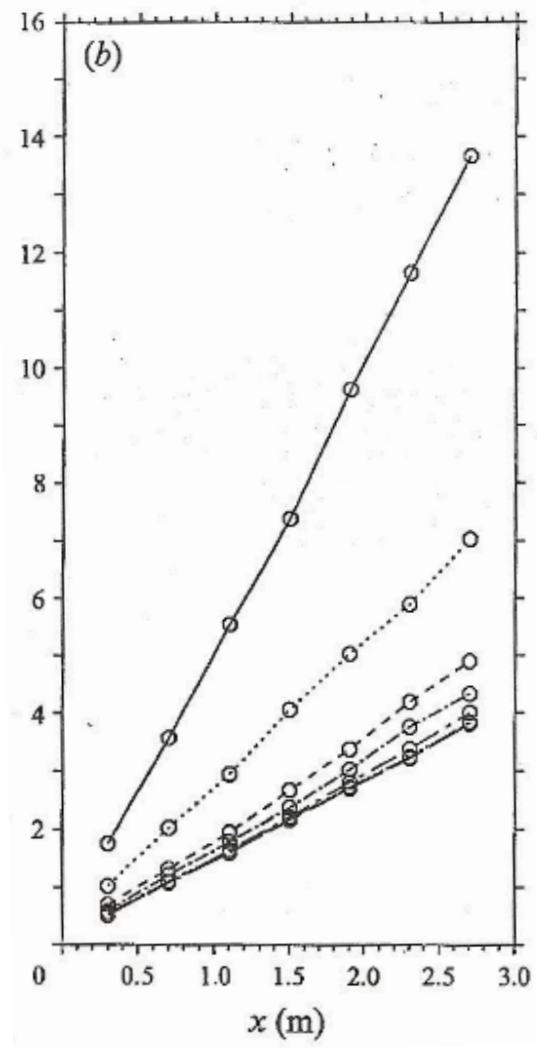

Figure 3. Propagation velocities of dense gas and light gases (Grobelbauser et al. 1993)—light gas. 
Table 1. Gas combinations used for Grobelbauser et al. (1993)'s experiment.

\begin{tabular}{|l|c|}
\hline \multicolumn{1}{|c|}{ Gases } & Density Ratio $\left(\boldsymbol{\rho}_{\mathbf{L}} / \boldsymbol{\rho}_{\mathbf{H}}\right)$ \\
\hline $\mathrm{CO}_{2} /$ Argon & 0.90 \\
\hline Argon/Air & 0.72 \\
\hline R22/Argon & 0.46 \\
\hline R22/Air & 0.33 \\
\hline Air/Helium & 0.14 \\
\hline Argon/Helium & 0.1 \\
\hline R22/Helium & 0.046 \\
\hline
\end{tabular}

The test-section was made of transparent Plexiglas to allow visualization. Along with the current speed, the current depths were of interest in the experiment. Some initial visualization trials were made using smoke from commercial smoke pellets. These pallets, however, generated smoke by burning and the heat released changed the density distribution. A second trial was performed using a method based on the evaporation of oil from a vertical wire. This method allowed them to obtain photos showing that the flow is not symmetric and the light-gas front is less blunt and appears more stable than the heavy-gas fronts. Still, they were unable to obtain good quantitative data of the current depth.

\section{NUMERICAL SIMULATIONS AND COMPARISONS}

FLUENT 6.3, a general purpose CFD code, was used to simulate the experiments. Figure 4 shows the geometry and mesh of the FLUENT model. Since the experiment by Grobelbauer et al. (1993) was based on the simple lock exchange flows in the rectangular channel, the 2-D assumption is reasonably valid here. The model consists of two boxes of different sizes. The left one is $0.3 \mathrm{~m}$ high and $3.0 \mathrm{~m}$ long. The right one is $0.3 \mathrm{~m}$ high and $0.8 \mathrm{~m}$ long. The mesh type is hexagonal, and three different sizes of mesh were considered in the grid sensitivity study: coarse, normal, and fine. The mesh sizes are $0.04 \mathrm{~m}$ (coarse), $0.02 \mathrm{~m}$ (normal), and $0.01 \mathrm{~m}$ (fine) for each grid. (a) Geometry

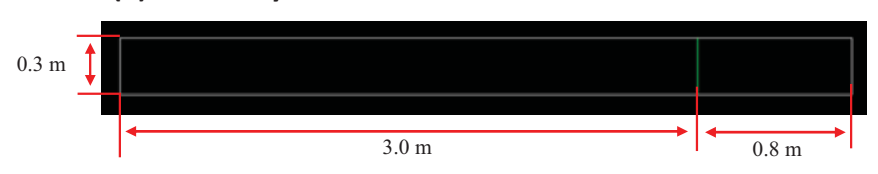

(b) Mesh

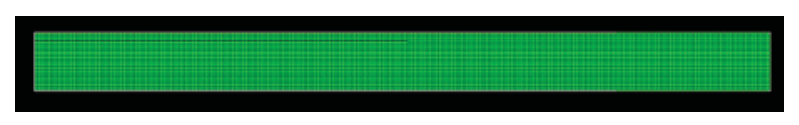

Figure 4. Geometry and FLUENT mesh.

The following data summarizes the FLUENT options and models used for the base calculations:

- Solver:

- Solver: Pressure Based

- Formulation: Implicit

- 2-D double precision

- Unsteady

- Velocity Formulation: Absolute

- Gradient Option: Green-Gauss cell based

- Pressure-Velocity Coupling: Simple

- Pressure: Standard

- Momentum: $2^{\text {nd }}$ Order

- Turbulence Kinetic Energy: $2^{\text {nd }}$ Order

- Turbulence Dissipation Rate: $2^{\text {nd }}$ Order

- Species: $2^{\text {nd }}$ Order

- Energy: $2^{\text {nd }}$ Order

- Viscous Model:

- Turbulence model: k-e realizable

- Wall function: standard wall function

- Energy equation

- Species transport model:

- 2 species: Air and Helium (for base case, see Table 1)

- Property Models:

- Density: Incompressible ideal gas

- Heat capacity: mixing law

- Thermal conductivity: mixing law

- Viscosity: ideal gas mixing law.

Figure 5 shows the initial simulation condition. The left hand side was filled with helium and the right hand side with air. This simulation demonstrates the heavy 
fluid intrusion into the light fluid. Initial temperature was set at $300 \mathrm{~K}$ and pressure at $1 \mathrm{~atm}$.

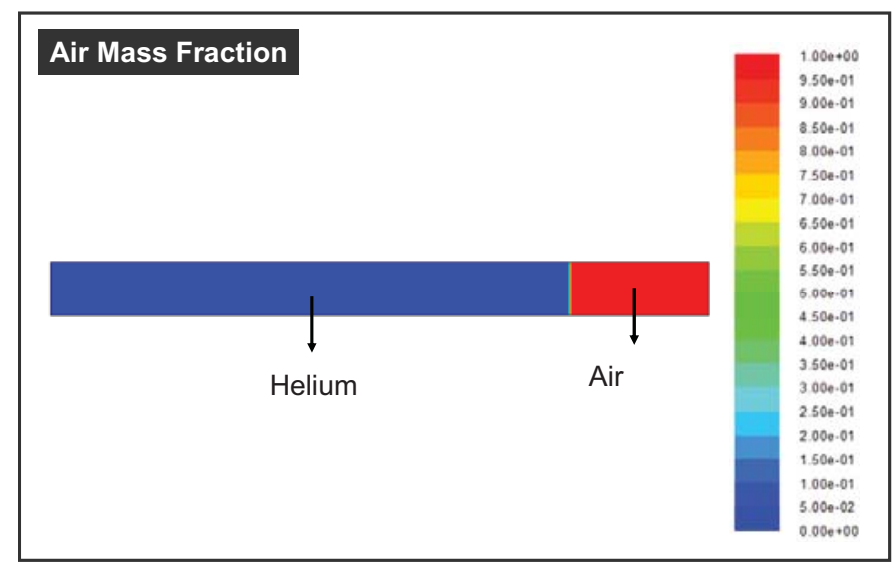

Figure 5. Initial air mass fractions.

Figures 6,7 , and 8 show the contour plots of air mass fractions at different times for fine, normal, and coarse meshes, respectively. These figures clearly show that air rapidly intrudes into the helium side. According to these figures, the front speed of the air looks constant along with time. They also show that air travels almost the same distance in the same time intervals, which strongly supports the invicid flow assumptions used in the previous theoretical derivations.

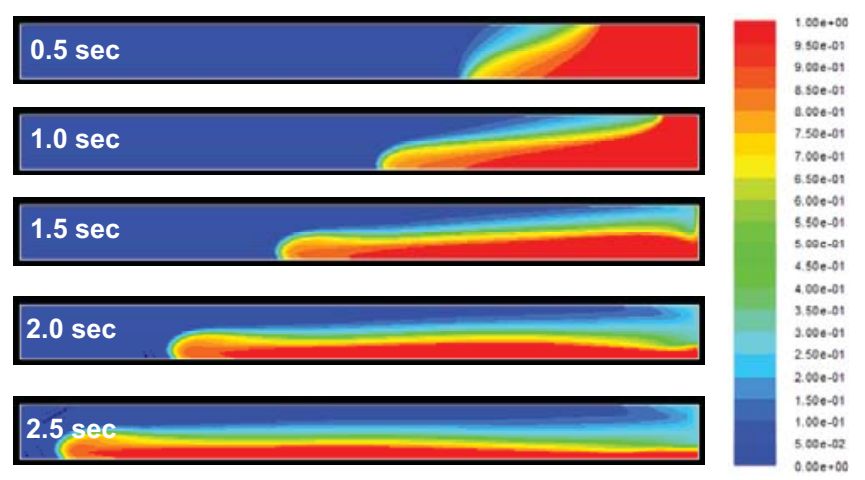

Figure 6. FLUENT simulations with fine mesh.

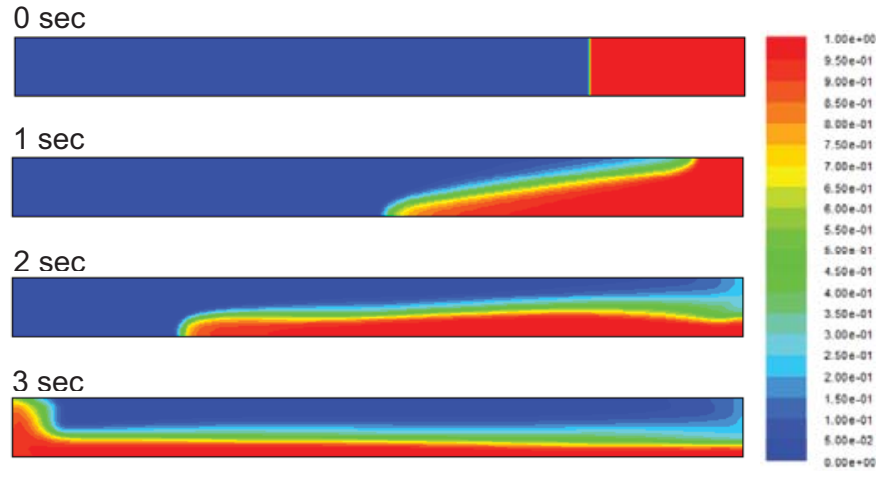

Figure7. FLUENT simulations with normal mesh.

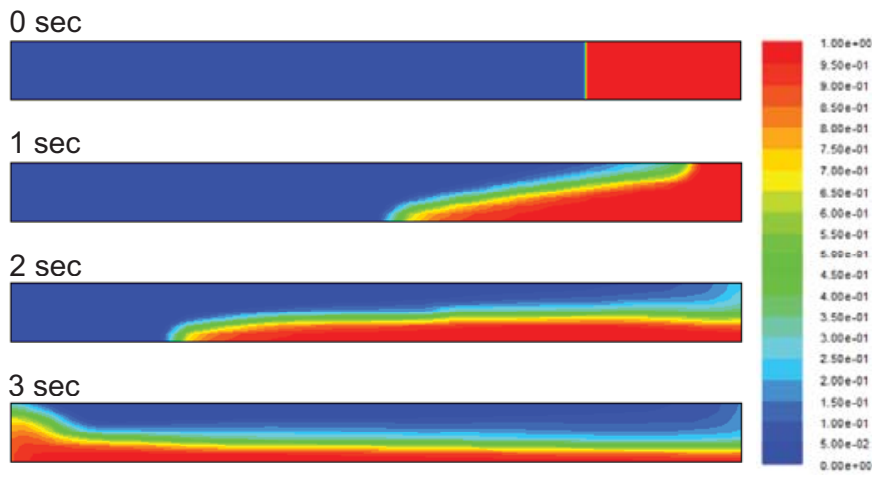

Figure 8. FLUENT simulations with coarse mesh.

A grid sensitivity study was performed for the simulation. Since the front speed is the main comparison parameter in the current validation, the current speed in the simulation was first defined with the same method used in the experiment. The locations of the current in the experiment were determined by hot-wires installed at the bottom of the test-section. Likewise, the current locations in the simulations were also determined by the air concentrations at the bottom plane.

Figure 9, which shows the air mass fractions at the bottom plane for five different curves and times: 0.5 , $1.0,1.5,2.0$, and 2.5 seconds. The current locations were determined to be the intersections between the air mass fraction curves and $\mathrm{x}$-axis. 


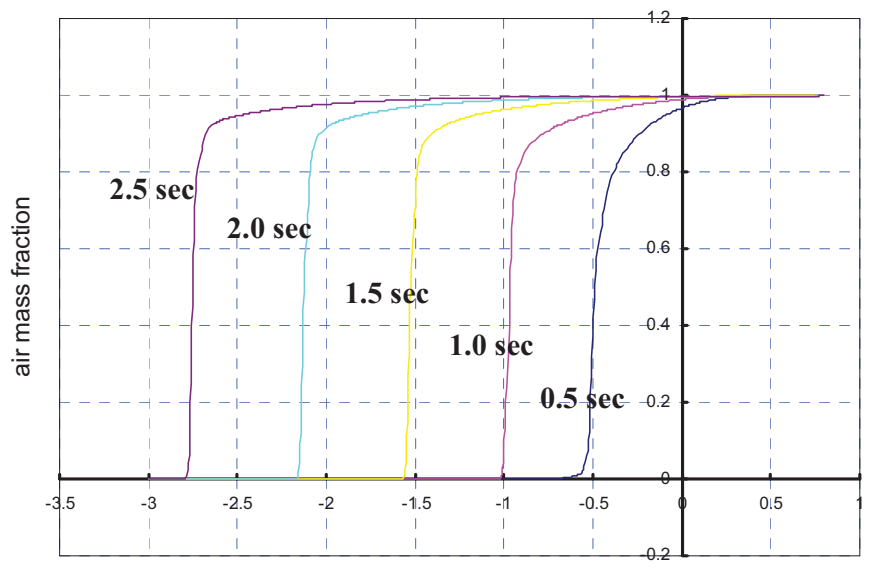

location $(x)$

Figure 9. Air mass fraction at the bottom plate (current locations).

Based on Figure 9, the propagation distances were obtained for different times. Figure 10 compares the calculated propagation distances for three different quality meshes. As shown, the calculated propagation distances are quite close to each other, even though the quality of the meshes differ. Especially, if looking at the data at $\mathrm{t}=2.5$ seconds, three different models predict almost the same propagation distances (within 1\%).

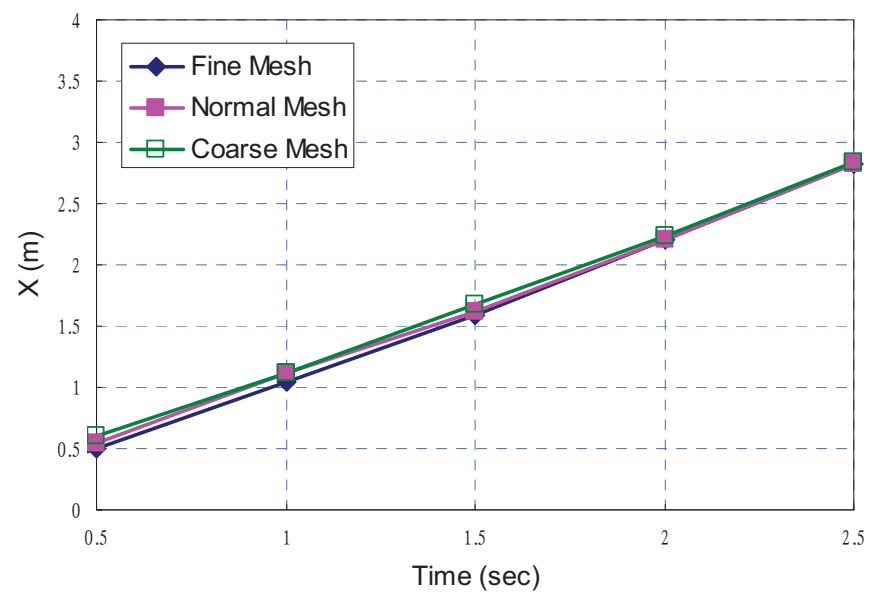

Figure 10. Comparisons between different meshes.

A method based on the Richardson extrapolation (Roache et al. 1998) was used to quantitatively estimate the grid convergence. The objective of this CFD analyses was to determine the current front speed along with the channel. Table 2 gives the grid information and calculated front speeds by CFD calculation. Each solution was converged with respect to iterations. The grid spacing column gives the spacing normalized by the spacing of the finest grid.

Table 2. Grid information and front speed.

\begin{tabular}{|l|c|c|}
\hline \multicolumn{1}{|c|}{ Grid } & $\begin{array}{c}\text { Normalized } \\
\text { Grid Spacing }\end{array}$ & $\begin{array}{c}\text { Front Speed } \\
(\mathbf{m} / \mathbf{s})\end{array}$ \\
\hline 1. Fine & 1 & 1.19 \\
\hline 2. Normal & 2 & 1.18 \\
\hline 3. Coarse & 4 & 1.16 \\
\hline
\end{tabular}

From the above information, the order of convergence is calculated as

$p=\ln ((1.16-1.18) /(1.18-01.19)) / \ln (2)=1$.

Applying the Richardson extrapolation using the two finest grids gives an estimate of the value of the front speed at zero grid spacing as

$V_{h}=1.19+(1.19-1.18) /\left(2^{1}-1\right)=1.2 \mathrm{~m} / \mathrm{s}$.

Figure 11 plots the simulated front speeds and the estimated front speed at zero grid spacing.

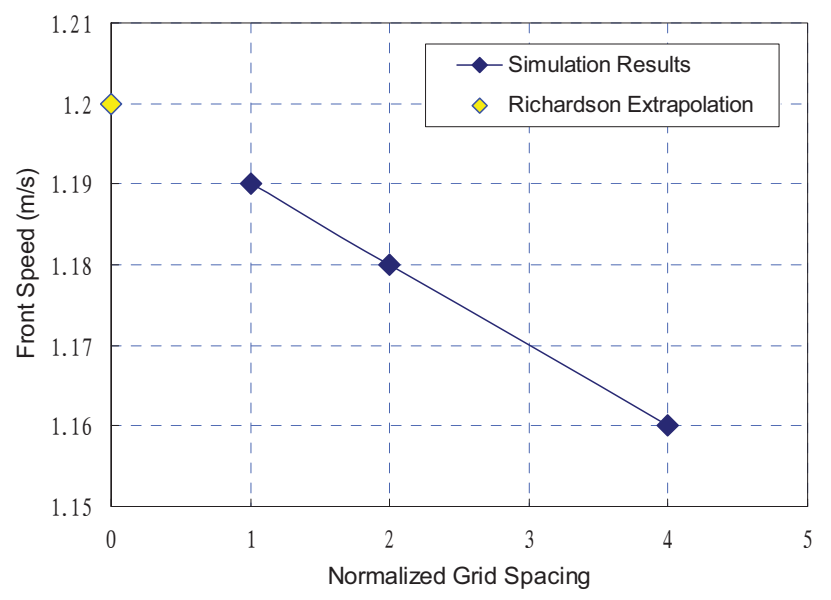

Figure 11. Simulated front spends and estimated front speed at zero grid spacing.

The grid convergence index (GCI) for the fine grid solution was computed using a factor of safety of $\mathrm{Fs}=1.25$. The GCI for grids 1 and 2 is

$\left.G C I_{12}=1.25 \times(1.19-1.18) / 1.19\right) /\left(2^{1}-1\right) \times 100=1.050 \%$

and the GCI for grid 2 and 3 is

$\left.G C I_{23}=1.25 \times(1.18-1.16) / 1.18\right) /\left(2^{1}-1\right) \times 100=2.119 \%$ 
The formula used to check that the solutions were in the asymptotic range of convergence is

$$
2.119 /\left(2^{1} \times 1.050\right)=1.0085
$$

which is approximately one, indicating that the solutions are well within the asymptotic range of convergence.

Based on the calculation in Equations 1 through 5, the front speed is estimated to be 1.2 within an error of $1.050 \%$. The front speed estimated in the fine mesh is only deviated from this value with an error of $0.84 \%$, indicating that the simulated results by fine mesh are quite reliable.

More calculations were carried out to investigate the turbulence model effect on the results. Figures 12, 13, and 14 show the contour plots on the air mass fractions for k-w, standard k-e, and RSM, respectively. All the simulations have been performed by using fine mesh grid and the same model setup as the base calculation except for turbulence models. The three figures show that the overall qualitative flow behaviors are not dependent on the different turbulence model.

Figure 15 shows the comparisons between the CFD simulation results and the experimental data. The compared parameter is the front location of the heavy current (air). This figure shows that the realizable k-e and RSM models are accurately predicting the front locations, where the data in the beginning shows more deviations than those in the later. This is because, in the actual experiment, the opening gate is not instantaneous, and the gate opening process disturbs the flow field. After 1 second, the experimental data and the CFD results show reasonably good agreement.

Table 3 summarizes the comparisons of the front speed between the experiment and the CFD simulations. To estimate the front speeds correctly, only the data after 1.5 seconds were used by ignoring initial disturbed data. The air current speed in the experiment was estimated to be $1.25 \mathrm{~m} / \mathrm{s}$. The calculated CFD results are $0.92 \mathrm{~m} / \mathrm{s}$ (standard k-e), $1.19 \mathrm{~m} / \mathrm{s}$ (realizable k-e), $1.12 \mathrm{~m} / \mathrm{s}(\mathrm{k}-\mathrm{w})$, and $1.20 \mathrm{~m} / \mathrm{s}(\mathrm{RSM})$. As shown in Table 3, the realizable k-e and RSM models accurately predict front speeds. The errors of the k-e model and the RSM model are $5.04 \%$ and $4.2 \%$, respectively.

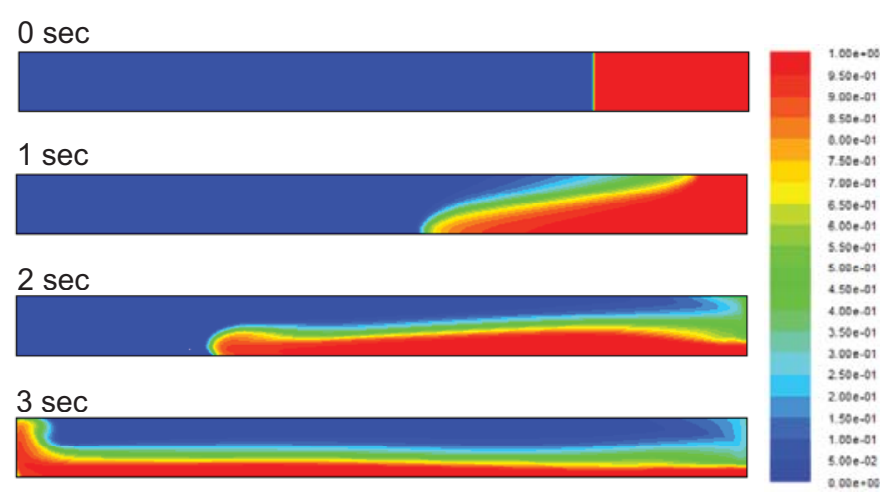

Figure 12. FLUENT simulation (air mass fraction, k-w model, fine mesh).

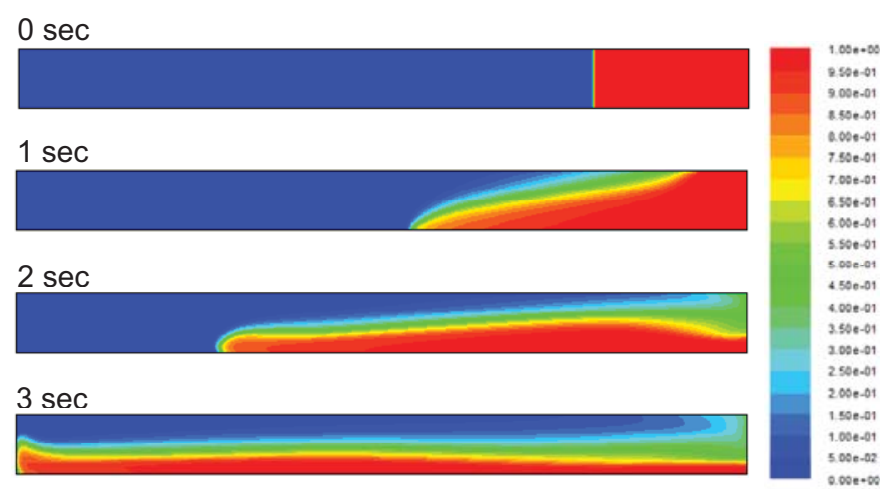

Figure 13. FLUENT simulation (air mass fraction, standard k-e model, fine mesh).

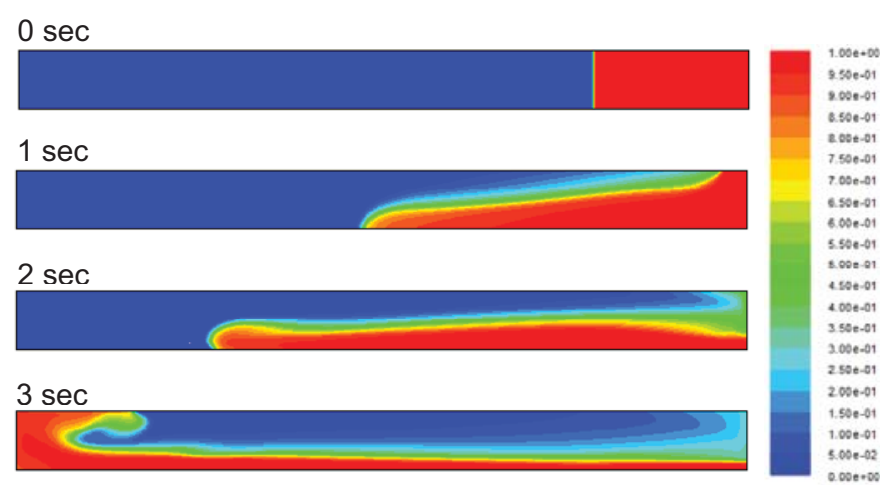

Figure 14. FLUENT simulation (air mass fraction, RSM model, fine mesh). 


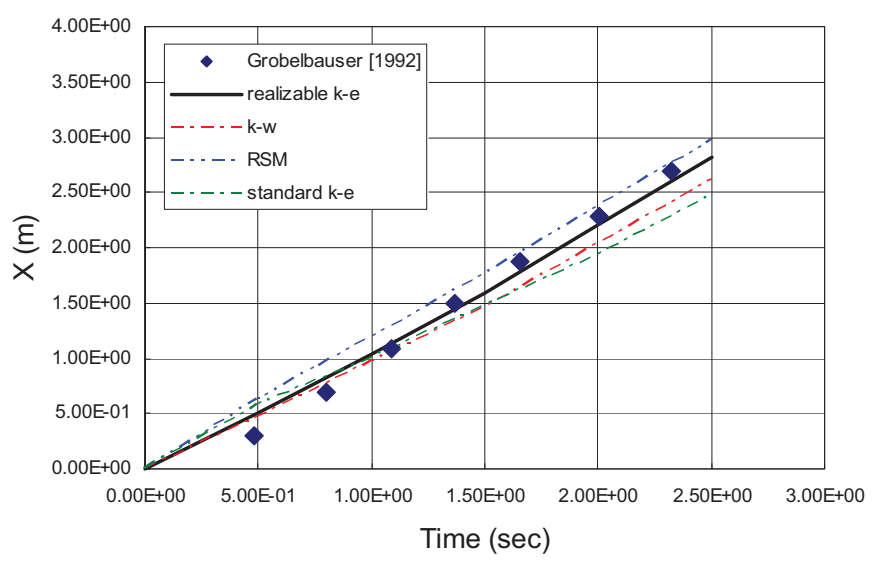

Figure 15. Comparisons between CFD results and experimental data (current speed).

Table 3. Comparisons between CFD results and experimental data (current speed).

\begin{tabular}{|l|c|c|}
\hline & $\begin{array}{c}\text { Current } \\
\text { Speed (m/s) }\end{array}$ & Error (\%) \\
\hline $\begin{array}{l}\text { Experimental Data } \\
\text { (Grobelbauer et al. 1993) }\end{array}$ & 1.25 & - \\
\hline Standard k-e model & 0.97 & 28.9 \\
\hline Realizable k-e model & 1.19 & 5.04 \\
\hline k-w model & 1.12 & 11.6 \\
\hline RSM model & 1.20 & 4.2 \\
\hline
\end{tabular}

In the above validation, heavy gas intrusion (air) into light gas (helium) has been taken into consideration, and the calculation results showed very good agreement with the experimental data. In the following section, the opposite case has been considered when the light gas (helium) is intruding into heavy gas (air). All the basic simulation set-ups are chosen to be the same as those used in the above simulation except for the initial air mass fractions. Figure 16 shows the initial air mass fractions assumed in the simulation, wherein the lefthand side is initially filled with air while the right-hand side is filled with helium. The realizable k-e model has been selected to be the reference turbulence model. The fine mesh has been used for calculations.

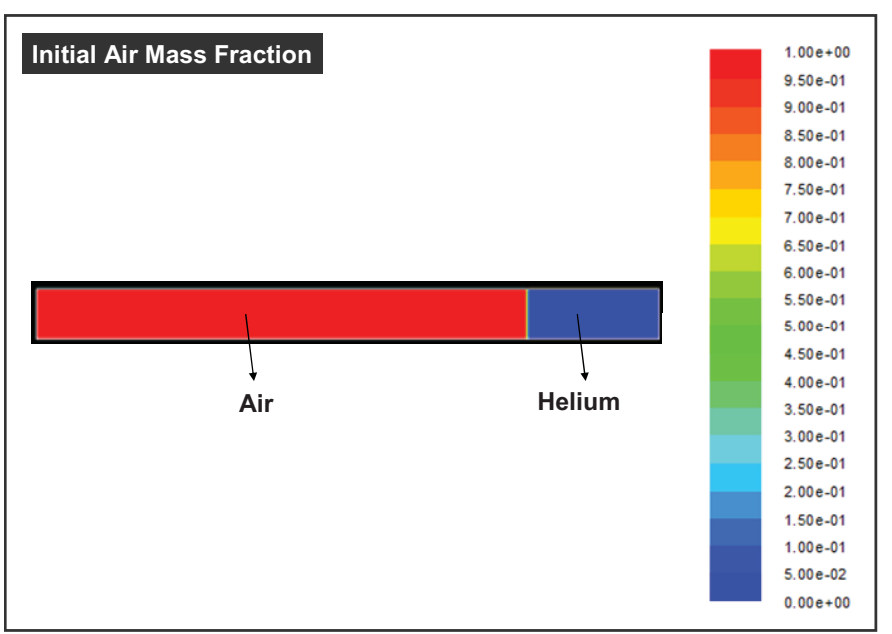

\section{Figure 16. Initial air mass fraction for light gas intrusion of helium.}

Figure 17 shows the calculated contour plots on air mass fraction for different times. The red color represents air and the blue color represents helium. Helium is smoothly intruded into the air side with almost constant speed occupying half of the channel height. It seems that the light current (helium) is showing perfect energy conserving flow, satisfying Benjamin's theory. This simulation result is also consistent with the previous experimental observations by Lowe et al. (2005).

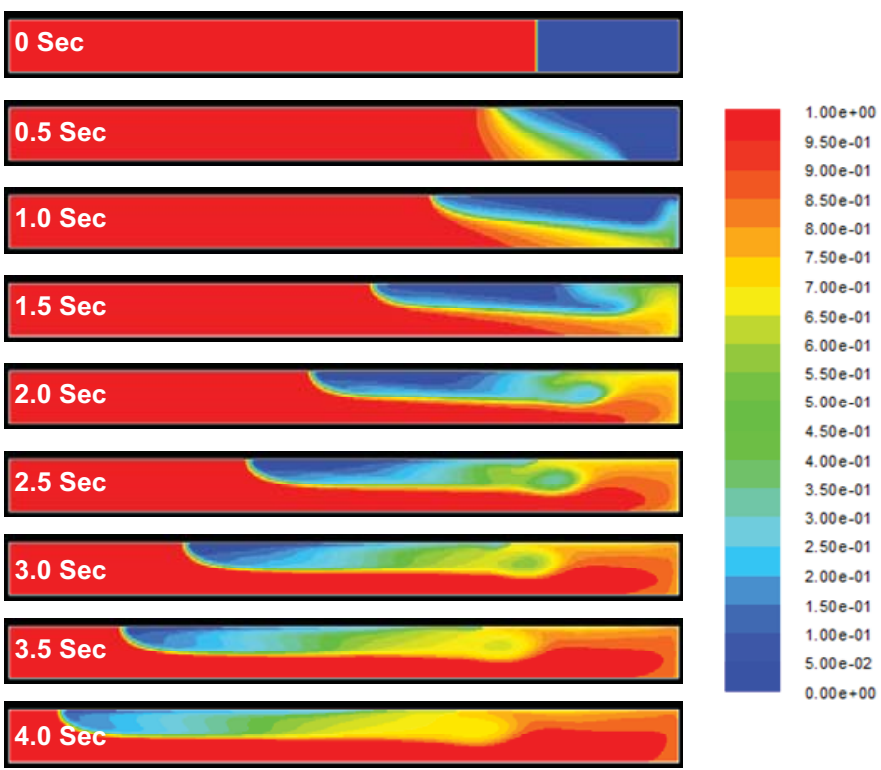

Figure 17. FLUENT simulation (air mass fraction, realizable k-e model, fine mesh).

To determine current locations, the helium mass fractions on the upper plate were plotted for different 
times as shown in Figure 18. The intersections between helium mass fraction curves and $\mathrm{x}$-axis were chosen as the current locations.

Figure 19 shows the comparisons on the current locations (helium) between experiment (Grobelbauer et al. 1993) and FLUENT simulations. The calculated results showed very good agreement with the experimental data. Table 4 summarizes the estimated current speeds. The current speed obtained by experimental data is $0.68 \mathrm{~m} / \mathrm{s}$ and that of simulation is $0.72 \mathrm{~m} / \mathrm{s}$. This result indicates that the deviation of simulation results from that of the experimental data is only $5.56 \%$.

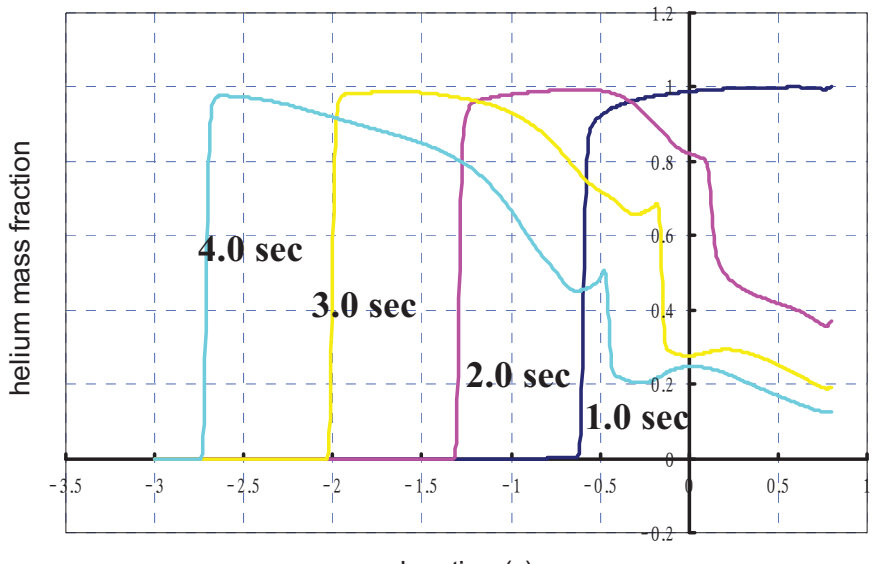

location $(\mathrm{x})$

Figure 18. Helium mass fraction at the upper plane for light gas intrusion.

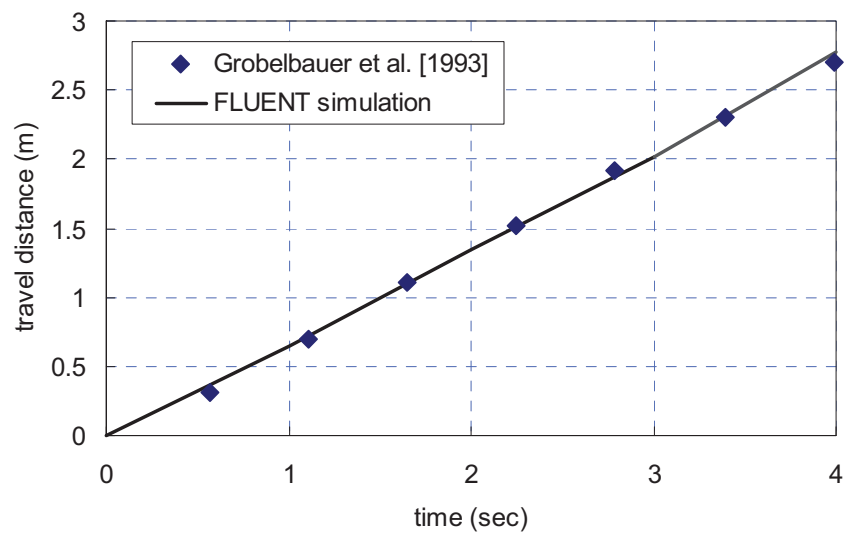

Figure 19. Comparisons between CFD results and experimental data (light gas intrusion).

Table 4. Comparisons between CFD results and experimental data (light gas intrusion).

\begin{tabular}{|l|c|c|}
\hline & $\begin{array}{c}\text { Current } \\
\text { Speed (m/s) }\end{array}$ & Error (\%) \\
\hline Experimental Data & 0.68 & - \\
\hline
\end{tabular}

\begin{tabular}{|l|l|l|}
\hline (Grobelbauer et al. 1992) & & \\
\hline $\begin{array}{l}\text { FLUENT (Realizable k-e } \\
\text { model) }\end{array}$ & 0.72 & 5.56 \\
\hline
\end{tabular}

\section{CONCLUSIONS}

Based on experimental lock exchange data using seven different sets of gases with density ratios from 0.046 to 0.9 , the experimental axial velocities agree very well with the predicted velocities from CFD calculations.

The grid sensitivity study used a method based on the Richardson extrapolation to estimate the grid convergence. Mesh sizes varied as follows: $0.01 \mathrm{~m}$ for the fine mesh, $0.02 \mathrm{~m}$ for the normal mesh, and $0.04 \mathrm{~m}$ for the coarse mesh. Using air as the heavier gas and helium as the lighter gas, the CFD-calculated front head speed of the fine mesh was compared with that of the zero spacing extrapolated by the Richardson method. The result for the CFD Calculation was $1.19 \mathrm{~m} / \mathrm{s}$ versus $1.2 \mathrm{~m} / \mathrm{s}$ for the zero spacing method, and experimental front head speed was $1.25 \mathrm{~m} / \mathrm{s}$.

The effect of turbulence models was also investigated. The realizable k-e turbulence model and Reynolds Stress Model were better than the standard $\mathrm{k}-\mathrm{e}$ and $\mathrm{k}-\mathrm{w}$ models.

\section{ACKNOWLEDGEMENTS}

This work was supported through the Department of Energy's NGNP Project under DOE Idaho Operations Office Contract DE-AC07-99ID13727.

\section{REFERENCES}

ANAYS FLUENT 6.3, User Guide, 2008.

Oh, C. H., Davis, C. B., Siefken, L. Moore, R., NO, H., Kim, J., Park, G. C., Lee, J., and Martin, W., Development of Safety Analysis Codes and Experimental Validation for a Very High Temperature Gas-cooled Reactor Final Report, INL/EXT-06-01362, March 2006.

Oh, C. H., Kim, E., Kang, H., NO, H., and Cho, N, FY-09 Report: Experimental Validation of Stratified Flow Phenomena, Graphite Oxidation, and Mitigation Strategies of Air Ingress Accidents, INL/EXT-09-16465, Revision 1, December 2009. 
Oh, C. H., Kim, E., Schultz, R., Patterson, M., and Petti, D., "Thermal Hydraulics of the Very High Temperature Gas Cooled Reactor," Proceedings of the 13th International Topical Meeting on Nuclear Reactor Thermal-Hydraulics (NURETH-13),

Kanazawa, Japan, October 2009.

Grobelbauer, H. P., Fannelop, T. K., and Britter, R. E., "The Propagation of Intrusion Fronts of High Density Ratios," J. Fluid Mechanics, Vol. 31, 1993, pp. 669-687.

Lowe, R. J., Linden, P. E., and Rottman, J. W., “A Laboratory Study of the Velocity Structure in an Intrusive Gravity Current," J. Fluid Mechanics, Vol. 456, 2002, pp. 22-48.

Lowe, R. J., Rottman, J. W., and Linden, P. F., “The Non-Boussinesq Lock-Exchange Problem. Part 1. Theory and Experiments," J. Fluid Mechanics, Vol. 537, 2005, pp.101-124.

Roache, P. J., Verification and Validation in Computational Science and Engineering, Hermosa Publishers, Albuquerque, New Mexico, 1998.

Shin, J. O., Dalziel, S. B., and Linden, P. F., "Gravity Currents Produced by Lock Exchange," J. Fluid Mechanics, Vol. 521, 2004, pp. 1-34. 